*Mestra em Direito em 2019 pela Universidade Federal da Bahia (UFBA)

Especialista em Direito em 2013 pela Universidade Católica do Salvador (UCSAL)

Especialista em Direito do Estado em 2017 pela Universidade Federal da Bahia (UFBA)

Graduada em Direito em 2009 pela Universidade Católica do Salvador (UCSAL)

E-mail: alessandra.schurig@ hotmail.com

** Pós-Doutor em 2012 pela Universidade Federal da Bahia (UFBA)

Doutor em Direito em 2001 pela Universidade Católica de São Paulo (PUC-SP)

Mestre em Direito em 1997 pela Pontifícia Universidade Católica de São Paulo (PUC-SP).

Especialista em Direito Administrativo em 1995 pela Universidade Federal da Bahia (UFBA).

Graduação em Direito em 1992 pela Universidade Federal da Bahia (UFBA)

E-mail: juliorochaufba@gmail. com

\section{A INFLUÊNCIA DO CONTEXTO ECONÔMICO NA INTERPRETAÇÃO JUDICIAL: NA VIDA A GENTE PEDE O QUANTO QUER E RECEBE O QUANTO PODE.}

\author{
THE INFLUENCE OF THE ECONOMIC CONTEXT ON \\ JUDICIAL INTERPRETATION: IN LIFE WE ASK FOR \\ AS MUCH AS WE WANT AND RECEIVE AS MUCH \\ AS WE CAN.
}

\section{Alessandra Cavalcante Scherma Schurig* Júlio César de Sá Rocha**}

Como citar: SCHURIG, Alessandra Cavalcante Scherma. ROCHA, Júlio César de Sá. A influência do contexto econômico na interpretação judicial: na vida a gente pede o quanto quer e recebe o quanto pode. WTO-OSC/ds267 - Pland Cotton. Scientia Iuris, Londrina, v. 23, n. 2, p. 147-165, jul. 2019. DOI: 10.5433/2178-8189.2019v23n2p147. ISSN: 2178-8189.

Resumo: O presente artigo tem por objetivo analisar a dialeticidade existente entre sistemas econômico, social e jurídico permitindo a rejeição de uma visão metafisica em favor de uma contextualização do direito em bases historicistas e contextuais, repensando o papel do Poder Judiciário diante da complexidade ambiental enfrentada pela hermenêutica judicial que deverá manter a juridicidade da compreensão e das respostas ao mesmo tempo que considera as racionalidades advindas dos demais sistemas.

Palavras-chaves: Economia; Direito; Interpretação; Sistemas.

Abstract: This article aims to analyze a dialectic between economic, social and legal systems, allowing the rejection of metaphysical in favor of a contextualization of judicial system on historical and contextual bases, rethinking the role of judicial power face off environmental complexity faced by judicial hermeneutics that should maintain the juridicity of comprehension and responses while considering the rationalities arising from other systems

Key words: Economy, Law, Interpretation, Systems. 


\section{INTRODUÇÃO}

Discorrer sobre a visão mais fundamental, inicial e simples sobre o que é um direito é uma via necessária para a abordagem posterior e mais complexa de temas hermenêuticos. Muitas vezes será a definição adotada do que é um direito que acaba por pautar todo o caminho argumentativo. Ou seja, será a base que irá traçar a hermenêutica posterior.

Assim, pode-se dizer que ao partir da definição de um direito como algo absoluto e ideal, isso trará como consequência a ideia de que ele deve ser defendido sob toda e qualquer circunstância. Por outro lado, se a concepção sobre o direito é de algo a ser realizado, a consequência é a observação do contexto e das circunstâncias para sua realização.

É possível definir que a hermenêutica judicial brasileira se pauta por uma visão metafísica ao responder sobre o que é um direito. Deste modo, parte-se da visão de direitos absolutos e imanentes que devem ser protegidos a qualquer custo e sob qualquer hipótese.

Doutrinadores que estudam a influência da metafísica na hermenêutica judicial e atentam para a intersecção entre sistemas, como Kaufmann (KAUFMANN, 2010) e Carneiro (CARNEIRO W. A., 2009) apontam que esse modo de visão sobre o direito no Brasil vem da brevidade do nosso período constitucional democrático que gerou a ausência de uma tradição hermenêutica democrática-liberal, somada à importação açodada de teorias.

A presente pesquisa desenvolveu-se visando demonstrar as raízes sociais e não metafísicas do sistema judicial normativo, permitindo que a partir do traçar de uma origem seja feita uma reflexão sobre o estado presente e o futuro da hermenêutica judicial.

Considera-se imprescindível que a visão metafísica sobre hermenêutica judicial seja questionada a favor de métodos contextuais ponderativos sobre a intersecção entre sistemas que ao mesmo tempo considerem a necessidade de manutenção da autonomia do sistema jurídico.

Antes de chegar no Brasil, parte-se da análise do sistema polinésio, em razão de ser um sistema social simplificado que permitiu que ficasse evidenciada a intersecção entre sistemas sociais, o que permitiu a rejeição da base metafísica para o sistema normativo.

A partir dessa base, mostrou-se a tensão entre os sistemas econômico e jurídico, a partir dos trabalhos de Faria (FARIA, 2010), Mascareño. (MASCAREÑO, 2011) e Carneiro. (CARNEIRO W. D., 2018).

Por fim, analisou-se decisão paradigmática do Supremo Tribunal Federal referente à ADIN 5486, na qual mostrou-se a dificuldade no trato judicial de temas econômicos relevantes, bem como demonstrar a falta de colegialidade na decisão, com ministros votando de forma isolada e com pouco rigor argumentativo, confirmando a impressão sobre a falta de debate e discussão dos temas julgados, tese já levantada por Pretzel (PRETZEL, 2014).

Enfim, ao partir do pressuposto de que um direito é algo a ser protegido que impõe obrigações, pode-se defender a visão de que um direito é o resultado do que uma sociedade diz sobre o que deve ser feito, fornecendo o ângulo absoluto que fornece a estabilidade (ASSIERANDRIEU, 2000, p. 143), o que é uma visão contextual e historicista sobre os direitos. 
Quem dará estabilidade à defesa do direito será uma sociedade determinada que decidiu assuntos e temas relevantes que devem defendidos. Desse modo, a justiça passa a não ser uma questão metafísica, mas uma questão mais próxima à visão de Rawls que percebe a justiça como a manutenção e proteção das instituições mais importantes de uma sociedade. (RAWLS, 2010, p. 18).

Analisar direitos sob essa perspectiva implica buscar um fundamento mais próximo a uma visão procedimental de justiça e direito do que uma discussão sobre fundamentos metafísicos que guiem o dever ser. Enfim, é se voltar para o campo da eficiência, da realização e da efetividade de direitos.

É o que observa o Ministro Barroso quando do julgamento da ADIN 5486 ocasião na qual desabafa que na vida, a gente pede o quanto quer, mas recebe o quanto pode.

Para entender importância dessa breve frase proferida pelo Ministro é preciso enxergar a intersecção existente entre sistemas e observar cuidadosamente a rede de influências recíprocas entre os sistemas sociais, algo que já foi feito com cuidado pela antropologia, demonstrando que não é preciso apelar para a metafísica nessa questão.

\section{A SIMBIOSE ENTRE DIREITO, ECONOMIA E SOCIEDADE VISTO ATRAVÉS DO KULA POLINÉSIO.}

Visando explicar como ocorre a dialeticidade entre os campos e como ocorre essa influência contínua e para isso é interessante perfazer observações de base empírica e discorrer sobre os estudos de Malinowski, antropólogo funcionalista que atuou na London School of Economics e construiu uma importante tese analisando os costumes de uma tribo da Papua-Nova Guiné.

Por haver uma complexidade menor no arranjo social, é um bom ponto de partida, inclusive por mostrar essa influência em um estágio pré-capitalista, o que permite compreender que o processo de troca de mercadorias é algo extremante relevante para a espécie humana como forma de satisfação de necessidades, mas não se resume a isso.

Outra conclusão interessante que pode ser extraída desse trabalho é de que direito e sua relação dialética com a sociedade e funções econômicas é algo que vai muito além de qualquer definição de manifestação social ocidental greco romana, "porque em toda parte há regras, em toda parte é segundo regras que se resolvem pendências, se regulam os comportamentos, se organiza a vida em grupo". (ASSIER-ANDRIEU, 2000, p. 89)

Malinowski tinha interesse em analisar a dialeticidade do processo econômico com a sociedade em questão e acabou por perceber como algo que podia em primeira análise ser tomado como um simples sistema comercial, o Kula, em verdade moldava os mais variados aspectos da vida daquela sociedade polinésia.

O antropólogo observou que este sistema comercial, o Kula, era um fenômeno econômico de considerável importância teórica que detinha um significado extremo na vida tribal dos nativos que vivem dentro do seu circuito. Ao mesmo tempo, Malinowski percebeu que a importância 
do sistema de trocas era totalmente reconhecida pelos nativos, cujas idéias, ambições, desejos e vaidades estão diretamente relacionados com o Kula (MALINOWSKI, 1976, p. 18)

O Kula sustenta-se na tradição e em costumes nativos baseados numa parceria permanente entre os indivíduos, implicando em confiança mútua, formando um sistema de trocas de artigos não vitais em grande escala. Trocam-se colares e braceletes de valor cerimonial. (MALINOWSKI, 1976, p. 91)

Até mesmo o aspecto mental dos nativos era modificado com o Kula, através da posse dos símbolos de riqueza, em uma demonstração de status social. Os objetos trocados detinham valor simbólico, representavam, como diz Malinowski, riqueza condensada, (MALINOWSKI, 1976, p. 390) tal qual o dinheiro para uma sociedade moderna.

Ora, se o dinheiro serve para circular, o mesmo ocorria com cada peça do Kula, denominadas vaygu'a. E cada objeto trocado era um meio de trazer renome social e distinção porque "um dos aspectos mais importantes e incomuns do Kula é a existência do vaygu'a kula, os objetos sempre trocáveis e de circulação incessante, que devem seu valor e seu caráter a esta própria circulação”. (MALINOWSKI, 1976, p. 390)

Destaque-se essa importância da circulação de mercadoria: é o processo de circulação de mercadoria o que gerava o valor da mercadoria, que em si, não tinha valor próprio, pois era apenas uma concha facilmente encontrada na região. Ainda outro aspecto que pode ser observado nessas sociedades polinésias e na sociedade moderna é o fato do valor do objeto ser também o resultado dos sentimentos do ato de troca, o que envolve a dimensão de status social. Cada ato de troca pode conferir dignidade e distinção aos envolvidos.

Ressalte-se que conforme destaca Malinowski, a ciência moderna já derrubou o mito do selvagem que vive no seio da natureza satisfazendo suas vontades. Em verdade, as sociedades nativas tinham um forte entrelaçado de deveres, funções, privilégios associados a uma organização tribal, familiar e comunitária complexa. (MALINOWSKI, 1976, p. 41).

Nessas comunidades que praticavam o Kula existiam líderes, trabalho em conjunto no sistema de trocas e lavoura e uma importante organização de cerimônias sociais e religiosas, com uma distribuição de assuntos importantes entre todos os membros. (MALINOWSKI, 1976, p. 63).

A riqueza da análise do sistema Kula permitiu que Malinowski percebesse, por exemplo, que até mesmo na pesca, se um dos pescadores respeita os horários definidos e locais de pesca é porque espera que o outro respeite do mesmo modo e isso era a base de uma harmonia social que poderia ser quebrada se o pescador não cumprir as regras, porque uma vez no Kula, sempre no Kula. (MALINOWSKI, 1976, p. 89).

E assim, paulatinamente, Malinowski demonstrou que o Kula não se tratava apenas de uma modalidade sub-reptícia e precária de troca. O Kula estava enraizado como uma importantíssima tradição e todas as suas transações eram públicas, com cerimônias organizadas e pré-estabelecidas, tendo um status fixo permanente, envolvendo a união de milhares de indivíduos. (MALINOWSKI, 1976, p. 91)

O Kula sujeitava-se a limites e regras rigorosos que não podiam ser descumpridos. A 
forma de troca, quem pode participar, as parcerias e relações que se formam, tudo era definido de forma organizada.

Até mesmo o lapso de tempo entre as transações era definido previamente e a relação de equivalência entre o que se recebeu e o que foi recebido, tudo como uma expressão de ordem, "como a configuração das obrigações que torna impossível ao indivíduo negligenciar sua responsabilidade sem sofrer por isso posteriormente." (MALINOWSKI, 1976, p. 66). Ou seja, todo o regramento do Kula era pré-estabelecido e sancionatório. Era preciso que as regras fossem seguidas, caso contrário gerava-se uma punição que deveria ser cumprida.

Pontue-se que essa visão permite que se defenda que a justiça não é o cerne metafísico do direito, um ideal para qual o direito converge e sim apenas a consequência da aplicação do direito, que é um sistema de ordenamento social que deseja prevenir conflitos e sancionar condutas desviantes. (ASSIER-ANDRIEU, 2000, p. 45).

Portanto, uma sociedade define o que é relevante e importante e a partir desse momento, será preciso que haja efetividade na defesa dessas questões. O que é relevante deve ser defendido e deve ser cumprido, sob risco de desconfigurar o sistema social. Se isso era verdade para o Kula, é também verdade para as sociedades contemporâneas.

É possível extrair visões interessantes do trabalho de Malinowski que mostra o entrelaçamento entre uma sociedade, seu sistema econômico e seu sistema jurídico mostrando que há uma dialeticidade constante entre as áreas e essa visão pode ser aplicada para outras sociedades.

Em sociedades em processo de desenvolvimento econômico e social, como a brasileira que enfrentou diversos processos de quebras e transições no campo normativo e no campo econômico, há uma simbiose que no mais das vezes é camuflada por uma visão metafisica na qual repousa a ideia de que os direitos elencados na Constituição Federal sejam realizados e efetivados em qualquer circunstância e sob qualquer contexto.

\section{A TENSÃO ENTRE O SISTEMA ECONÔMICO E O SISTEMA JURÍDICO.}

Há uma delicadeza na relação entre sistemas econômico e juridico que deve ser observada com cuidado, ainda mais em razão da incerteza e dos riscos da contemporaneidade que luta com o ajuste da economia perante expectativas normativas. (MASCAREÑO, 2011).

Nesse sentido, é importante destacar que em especial na passagem do século XX para o XXI ocorreram uma série de mudanças tecnológicas que impactaram o direito. Com a limitação da crença no poder dos Estados, ocorre uma expansão do setor privado que busca cada vez mais a auto regulação.

Dentre os diversos fenômenos no campo econômico que ocorreram, destacam-se, conforme Faria, "as novas formas de configuração de poder decorrentes do aumento do intercâmbio comercial em mercados intercruzados; a internacionalização do sistema financeiro; e o surgimento de novos produtos "descolados" do sistema produtivo e "derivados" dos tradicionais títulos e ações" (FARIA, 2010, p. 18).

Há uma rejeição de uma visão moral tradicional e os conceitos de moral e ética vem 
passando por transformações, buscando inclusive lidarem com estruturas semânticas mais maleáveis que possam lidar com a contingência de sentido. (MASCAREÑO, 2011).

Uma dessas estruturas semânticas maleáveis são justamente o campo dos direitos fundamentais que a partir dessa luz podem ser tomados como estruturas tendentes a funcionarem como eclusas, refletindo o entorno do sistema juridico, sintetizando racionalidade prática dos demais sistemas, a evolução de expectativas normativas e a reprodução interna da complexidade do entorno do sistema jurídico. (CARNEIRO W. D., 2018).

Ver direitos fundamentais como estruturas maleáveis que permitam o olhar do direito para o entorno enquanto ainda garantem a juridicidade da compreensão é uma ideia distante de uma interpretação judicial dogmática e canhestra que se paute por conceitos essencialistas, representacionistas e arcaicos.

De fato, o sistema jurídico, assaltado continuamente com a complexidade crescente de seu entorno, vem se negando a lidar com questões que são essenciais e resta clara a necessidade do campo jurídico lidar com essas questões e garantir a juridicidade da compreensão, ofertando respostas jurídicas para problemas sociais altamente complexos.

Nesse passo, com o aumento de fenômenos econômicos, a alta complexidade desses fatores e das sociedades pós-modernas, vem ocorrendo um progressivo esvaziamento do poder do Estado como única fonte produtora do direito.

Há um enfraquecimento do ideal de Estado justamente porque se questiona qual o papel desse mesmo Estado. Seria redistribuir renda? Seria exercer o papel de monopólio da coerção do direito? Seria integrar a comunidade? Quanto mais há trocas comunicacionais mais se questiona o papel que deve ser assumido pelo sistema jurídico.

E com esse enfraquecimento, exsurge a força do sistema econômico e financeiro frente a todas as demais facetas da sociedade, inclusive com o predomínio do sistema financeiro internacional sobre qualquer tentativa local de normatização. É o chamado "policentrismo decisório" (FARIA, 2010, p. 37) que dilui a autoridade em diversas entidades e comandos, ocasionando uma diferenciação do papel estatal, colocados entre esse poder financeiro que não pode ser ignorado e as demandas internas que muitas vezes replicam as demandas desse poder.

Colocado frente a isso, os Estados tomam medidas de esvaziamento do direito. Primeiramente com a legislação simbólica. Pressionado com o esvaziamento do poder, as demandas internas e as exigências de desenvolvimento econômico, o Estado passa a tratar o direito como um fim em si mesmo, descolado da realidade na qual deveria beber sua fonte.

Essa legislação simbólica acarreta o problema da aplicação, que se torna impossível, violando a autonomia e a segurança do Poder Judiciário. Ou seja, a crise no direito positivo acarreta a utilização exacerbada de conceitos indeterminados no direito e essa indeterminação legal parece, em primeiro momento, melhor do que precisão porque a lei escrita não consegue abarcar todos a complexidade dos fenômenos sociais. Mas a situação não é assim, tão superficial.

Isso porque essa indeterminação, essa imprecisão de conceitos passando a ser o comum mostra que o direito começa a ter seu conteúdo determinado muitas vezes no momento da 
aplicação, através de um processo de atribuição de conteúdo altamente diversificado.

Nesse processo cabe ao julgador dizer que está aberto para as esferas não jurídicas e olhar para o que está fora do direito. Sua grande tarefa, seu desafio, é reproduzir em conceitos jurídicos tudo que é externo ao direito.

Ocorre que essa tarefa de interpretação representa um deslocamento de uma delicada certeza que se acreditava existir no direito positivo para um papel cada vez mais relevante ofertado ao intérprete. É quase um deslocamento do centro do direito para a decisão judicial, como se não existisse direito antes da aplicação. Desse mesmo intérprete é exigido que se atenha aos procedimentos de interpretação jurídica, é imposto o dever de manter-se dentro das margens de enxergar o fato e interpretar o fato segundo regras do direito. E desse intérprete também se exigem soluções para as crises que perpassam todos os setores sociais e ele passa a lidar com fatos que transbordam as margens jurídicas.

Paulatinamente, o intérprete percebe: é impossível ignorar o campo econômico. Mas como evitar ser engolido por ele? Essa é a tarefa que angustia os intérpretes e aplicadores do direito na contemporaneidade. Eles sabem que ignorar a economia torna o direito uma ficção. Eles vêem que princípios como "proibição de retrocesso" são questionados.

Já alertava Calmon de Passos, "enquanto textos, as decisões são inócuas. Sua eficácia e efetividade ocorrem com a execução do julgado”. (PASSOS, 2013, p. 211). E assim surgiu a chamada jurisprudência da crise. Uma jurisprudência que reflete a atual situação econômica mundial de dificuldades e incertezas.

Por ter ignorado tempo demais o aspecto econômico, o direito passou a ser impactado diuturnamente com a economia e engolido por esta, negando sua própria autonomia com "a dramática aceitação de 'menos trabalho e menos salário, mas trabalho e salário e para todos', o desafio da bancarrota da previdência social, o desemprego duradouro, parecem apontar para a insustentabilidade do princípio da não reversibilidade social." (CANOTILHO, 2015) são todos fatores que impactam inegavelmente o sistema jurídico.

Carneiro aponta que o sistema quando se depara com complexidade em demasia, busca resolver através de antigos modelos hermenêuticos silogísticos ou modelos argumentativos com vocação dogmática, sem sucesso. (CARNEIRO W. D., 2018).

Mas o sistema econômico segue influenciando o direito e não há mais escapatória, ou se lida ou se perece. Se a economia é a ciência pela qual o homem estuda como suprir suas necessidades infinitas com recursos escassos, e o direito é o modo pelo qual o homem busca a justiça, e se os dois campos estão entrelaçados no mundo e por isso no intérprete, e vice e versa, como poderia ser possível considerar a possibilidade de ignorar a economia no processo de compreensão do direito?

As necessidades de uma comunidade são infindáveis, os recursos são escassos e sendo assim, para que o direito se mantenha coerente com a racionalidade jurídica e ao mesmo tempo considere o aspecto econômico, o intérprete deve considerar que o direito tem um custo e isso vai implicar em uma escolha que pode ou não ser feita por esse intérprete. E essa escolha precisa 
ser realizada do modo mais claro possível, para que possa ser compreendido que escolher algo significa também deixar de escolher.

E esse processo de escolha não é vergonhoso, não é imoral. É um processo natural, terreno e que deve ser desenvolvido abertamente sem que seja preciso apelar para conceitos absolutos, metafísicos.

Em regra, o papel de realizar escolhas e desenhar o orçamento cabe ao Poder Legislativo, que seria em nosso sistema democrático o órgão por excelência desenhado para a questão, ampla tribuna democrática que permite discussão e acesso aos temas orçamentários e uma visão e discussão dos trade offs realizados.

Contudo, situações ocorrem e se multiplicam nas quais o Poder Judiciário é instado a definir se os atos dos demais poderes padecem de vícios de ilegalidade que o maculem de forma grave. E assim o Poder Judiciário paulatinamente tem sido obrigado a manifestar-se sobre diversas questões definidas como "extra-jurídicas".

E quando ocorrem essas situações nas quais o Poder Judiciário é instado a decidir sobre as questões orçamentárias, como deve ocorrer sua atuação? Se é certo que as situações são extra-jurídicas, seria possível o uso de argumentos extra-jurídicos sobre o tema? Poderia o Poder Judiciário organizar e incrementar o orçamento público, ditar políticas públicas e o rumo do governo, tudo com vistas ao ideal constitucional?

\section{CONSIDERAÇÕES E ANÁLISE DO ACÓRDÃO DA ADIN 5486 PELO SUPREMO TRIBUNAL FEDERAL.}

Todas as reflexões sobre direito e sistema econômico podem ser vistas através de um exemplo prático: a ADIn 5.486 proposta pela Associação Nacional dos Magistrados da Justiça do Trabalho- ANAMATRA. A ADIN 5468 gerou a seguinte tese de controle concentrado:

Salvo em situações graves e excepcionais, não cabe ao Poder Judiciário, sob pena de violação ao princípio da separação de poderes, interferir na função do Poder Legislativo de definir receitas e despesas da administração pública, emendando projetos de leis orçamentárias, quando atendidas as condições previstas no art. $166, \S 3^{\circ}$ e $\S 4^{\circ}$, da Constituição Federal

É um caso atual e relevante para que se possa tratar da tensão entre o direito e a realidade econômica, além da possibilidade de verificar como o direito lida quando o campo econômico entra em choque com o ideário juridico, além de verificar a impossibilidade de uma ratio decidendi que possa ser atribuída ao colegiado.

Preliminarmente já se deve considerar que as ministras Rosa Weber e Carmem Lucia e o ministro Toffoli acompanharam o relator pela improcedência e não teceram maiores considerações, fazendo apenas observações pontuais ao longo do julgamento, o que não permite uma análise profunda do seus posicionamentos. 
Em regra, pode-se inferir que ao seguir o relator, seguiram também suas razões de decidir, mas de fato, como ressalta Pretzel, é mais complicado compreender se a decisão apoiada no voto do relator (ou redator para o acórdão) é resultado de um consenso não declarado ou, ao contrário, equivale apenas a uma decisão monocrática tomada no âmbito do plenário (PRETZEL, 2014, p. 13).

Por sua vez, o ministro Marco Aurélio não adentrou no mérito por considerar a ANAMATRA ilegítima para opor ação de controle concentrado e sua decisão apoiou-se em precedentes anteriores que também debatiam a legitimidade da ANAMATRA para ações constitucionais de controle concentrado nas quais se exige a pertinência temática.

Portanto, a análise das razões de decidir no presente trabalho foi feita através dos votos dos demais ministros, tanto os que votaram pela procedência como os que votaram pela improcedência, esta última escolha de uma minoria formada por dois ministros, Celso de Mello e Ricardo Lewandowski.

Partindo do início, sabe-se que a Constituição Federal de 1988 definiu que cabe precipuamente ao Poder Legislativo definir as questões orçamentárias, inclusive proibindo medidas provisórias ou a delegação de matérias orçamentárias. E por outro lado, assegurou a autonomia ao Poder Judiciário para elaborar sua proposta orçamentária.

Essa autonomia orçamentária e financeira assegurada ao Poder Judiciário assegura a este poder elaborar e apresentar suas propostas orçamentárias, posteriormente encaminhadas ao Poder Executivo, segundo ditames constitucionais precisos.

Ressalte-se, conforme relembra o Ministro Luiz Barroso que "o Poder Judiciário tem a prerrogativa de formular o seu próprio orçamento não significa que tem o direito de receber tudo o que pediu. Na vida a gente pede o quanto quer e recebe o quanto pode". (SUPREMO TRIBUNAL FEDERAL, 2017, p. 82).

Em 2015, o Poder Judiciário encaminhou sua proposta orçamentária ao Executivo, e ao fim o Poder Legislativo modificou a proposta enviada. Isso ocasionou o manejo da ação constitucional ADIN 5468, oposta pela ANAMATRA, com a alegação de ocorrência de ofensa à clausula pétrea que define a separação de poderes, por conta de suposta intervenção do Poder Legislativo na proposta orçamentaria formulada pelo Judiciário em 2016. Impugnou-se valores que passaram a ser atribuídos à Justiça do Trabalho, tendo sido proposta a ADIN para avaliar se a deliberação efetuada pelo Poder Legislativo federal e implementada na LOA/2016 foi, ou não, ilegítima.

Alegou-se que teria ocorrido um desvio de finalidade haja vista o relatório da Comissão Mista de Planos, Orçamentos Públicos e Fiscalização (CMO) do Congresso Nacional deter uma assim chamada "motivação ideológica enviesada" porque o deputado relator manifestou, segundo a ANAMATRA pontuou na exordial "seu desejo de retaliação ao regular exercício da jurisdição trabalhista, uma vez que esse juízo político-orçamentário não se fundaria na realidade financeira da União e buscaria fim reprovável, isto é, a redução da capacidade judicial para tratar a litigância trabalhista”. (SUPREMO TRIBUNAL FEDERAL, 2017, p. 71)

A ANAMATRA considerou que a motivação do relator gerou um prejuízo irreparável e 
um desvio de finalidade, vulnerador da autonomia do Poder Judiciário e diante desse quadro, a exordial da ADIN tinha por pedidos a suspensão da eficácia do orçamento da Justiça do Trabalho contida no Anexo IV da Lei Orçamentária Anual de 2016, com os cortes que foram realizados e consequentemente a execução de $100 \%$ da proposta orçamentária original. Alternativamente, requeria que o corte no orçamento da Justiça do Trabalho fosse o mesmo no mesmo percentual dos cortes aplicados aos demais órgãos do Poder Judiciário da União, de $15 \%$ e não de $29 \%$ no custeio e de $40 \%$ no investimento e não $90 \%$ como foi definido após a alteração pelo Poder Legislativo.

Eis a situação colocada para julgamento pelo Supremo Tribunal Federal e isso posto, passa-se para qual será o modo de realização do julgamento. Quais os parâmetros que poderão ser utilizados? Deve haver o uso de uma racionalidade jurídica pura, deve-se utilizar a racionalidade jurídica temperada pela economia ou uma racionalidade apenas econômica?

Esse julgamento é representativo desse desafio que já foi inúmeras vezes enfrentado pelo direito: como manter o paradigma da racionalidade jurídica frente às pressões econômicas. Nesse sentido, o próprio caso em si já representa uma mudança na jurisprudência. Explica-se: a jurisprudência sobre a possibilidade do Poder Judiciário decidir questões orçamentária sofreu severas mutações ao longo dos anos, com idas e vindas.

Conforme destacado pelo ministro relator, Luis Fux, essa não é uma matéria já consolidada, é uma propensão, tão somente: "Preliminarmente, destaco que a possibilidade do "controle material" de espécies legislativas orçamentárias corresponde a uma tendência recentemente intensificada na jurisdição constitucional do Supremo Tribunal Federal (STF)." (SUPREMO TRIBUNAL FEDERAL, 2017, p. 14)

Essa nova tendência, com a admissibilidade da ocorrência de controle abstrato de leis orçamentárias iniciou-se no julgamento da Medida Cautelar na ADIn 4.048-MC/DF com relatoria do Min. Gilmar Mendes. Depois, houve o julgamento da medida cautelar na ADIn 3.949/DF, sob a relatoria do mesmo ministro.

Assim, paulatinamente, foi sendo gestada nova jurisprudência que superava a anterior que defendia posicionamento oposto, conforme pode ser observado na ADIn $\mathrm{n}^{\circ}$ 2.484-MC com a defesa de que a lei de diretrizes orçamentárias que tenha objeto determinado e destinatários certos, sem generalidade abstrata, é lei de efeitos concretos, e não está sujeita à fiscalização jurisdicional no controle concentrado.

Como visto, esse precedente foi sendo superado até que se chega à presente ADIN 5468, onde se defende abertamente a possibilidade de controle abstrato de constitucionalidade de normas orçamentárias, mesmo confrontado o caráter concreto dessa espécie normativa.

Houve uma mudança significativa de postura: O Poder Judiciário antes preferia aterse a outras questões e deixar que o orçamento fosse decidido pelo Poder Legislativo, mas hoje acredita que pode decidir sobre questões orçamentárias. Mas seria o Poder Judiciário o mais bem posicionado para decidir questões orçamentárias?

Como questiona Sunstein, "porque os juízes deveriam, focados estritamente nos casos trazidos a eles, ter o poder de decidir que o dinheiro dos contribuintes deve ser gasto (...)?" 
(SUNSTEIN, The Cost of Rigths, 1999, p. 26). É uma questão relevante.

Via de regra, acredita-se que o Poder Legislativo é quem tem as ferramentas necessárias para decidir sobre questões orçamentárias e a própria Constituição Federal tratou do tema dessa maneira.

Contudo, em virtude dos fatos explicados em tópico anterior, é o Poder Judiciário que vem sendo chamado para dar um choque de realidade nas pretensões orçamentárias formuladas pelo Legislativo. Mas isso é uma afronta à separação de Poderes ou algo inexorável frente à complexidade das situações enfrentadas?

Pode-se pensar que o caminho do meio seria o mais razoável. Ou seja, nem o Poder Judiciário se negaria a resolver questões que lhe são propostas, nem adentraria em profundidade em questões de elaboração orçamentária. Isso significa a escolha de uma postura de interpretação, dentre duas posturas possíveis, a minimalista ou maximalista:

Nesse sentido, o esgotamento dos fundamentos estará vinculado à concepção que a corte tem sobre o seu papel ao julgar os casos: deve ela se ater aos aspectos suficientes para o deslinde da questão ou deve ela se manifestar também sobre outros problemas, construindo uma doutrina constitucional que aponte para a sociedade respostas futuras? Trata-se de uma discussão em torno da postura minimalista ou maximalista de um tribunal. (PRETZEL, 2014, p. 13).

E nesse sentido, um início de solução pode ser apontado quando Sunstein elabora o que ele chama de "acordos teorizados de modo incompleto" (Incompletely theorized agreements) o que significa adotar uma postura pela qual o intérprete judicial não vai se recorrer a altos níveis de abstração e fará apenas o necessário para que o problema seja resolvido. Porque pode haver concordância no resultado e discordância em altos níveis de abstração. (SUNSTEIN, 1995, pp. 13, tradução nossa). Seria a adoção da postura minimalista na interpretação judicial.

Perceba-se que o orçamento foi colocado pela Constituição como uma questão precipuamente de decisão sob a tutela do Poder Legislativo porque este representa uma arena de debate público necessária para que se decidam as questões orçamentárias. Conforme ressalta o ministro Barroso:

Na maior parte das democracias do mundo, o momento da elaboração do orçamento é o momento do grande debate público, em que você vai definir quanto vai para a educação, quanto vai para a saúde, quanto vai para fazer estrada, quanto vai para o Poder Judiciário, quanto vai para a publicidade institucional. Este é um não debate no Brasil. A gente discute extensamente a judicialização, que é a ponta final, mas a gente discute pouco o momento politicamente mais grave, que é momento em que se fazem as grandes escolhas de um país, às vezes as escolhas trágicas e às vezes as grandes definições ideológicas de onde se vai colocar o dinheiro (SUPREMO TRIBUNAL FEDERAL, 2017, p. 82).

Seguindo o debate sobre os custos do direito, considerando os trade offs existentes, considerando a necessidade do direito não ser apenas linguagem, mas ter uma esfera de efetividade, qual seria o cenário de realidade econômica nesse julgamento? 
A realidade que motivou o PLOA de 2016 era crítica. Como consequência da crise econômica enfrentada no Brasil desde meados de 2014, havia queda acentuada no PIB e, por conseguinte, a queda na arrecadação:

O próprio Poder Executivo, no Ofício interministerial 093/2015/MF/MPOG, de 27/10/2015, no qual propôs alteração do $\operatorname{PLN~n}^{0} 5 / 2015$, que trata da redução da meta de resultado primário constante da LDO 2015, reviu a estimativa de queda do PIB para 1,0\%. Informações complementares relativas às projeções oficiais das principais variáveis ficaram disponíveis em 15 de setembro e foram atualizadas pelo Poder Executivo em 20 de novembro, por meio do Ofício $\mathrm{n}^{\circ}$ 230/2015-MP, indicando queda de $1,9 \%$ do PIB, parâmetro que foi adotado no Relatório da Receita. Cumpre lembrar que o PLOA 2016 foi encaminhado inicialmente com um déficit de R\$30,5 bilhões. Posteriormente, o Poder Executivo propôs reduções de despesas num montante de R \$ 26,9 bilhões. Por sua vez, as avaliações realizadas pelo Comitê de Receitas, com base na revisão dos parâmetros econômicos, apontaram um acréscimo líquido de receitas de R\$ 39,5 bilhões para 2016 (CÂMARA FEDERAL, 2016, p. 34).

A queda no PIB trazia como uma de suas consequências uma diminuição na arrecadação que implica em menor disponibilidade de receita para ser distribuída. Menos recursos implica em escolhas mais duras, em trade offs que nem sempre são visualizados, mas que precisam ser vistos e debatidos.

O ideal, conforme dito, era que o debate se processasse no momento de elaboração do orçamento, de forma clara e com participação popular, mas ao chegar uma ação que analise a legalidade desse debate e da formação das normas orçamentárias, como deve agir o Poder Judiciário? Uma tentativa de minimalismo pode ser encontrada no voto do ministro Edson Fachin que buscou analisar o caminho da proposta orçamentária segundo os ditames constitucionais:

Nos estritos limites interpretativos da normatividade constitucional, extrai-se que o Poder Executivo só pode tomar iniciativas unilaterais em relação à proposta orçamentária dos Poderes e órgãos dotados de autonomia orçamentária nas seguintes hipóteses: (i) não encaminhamento tempestivo da proposta; ou (ii) desacordo com os limites conjuntamente estipulados na Lei de Diretrizes Orçamentárias. Após o envio do projeto de lei, compete ao Parlamento apreciá-lo na forma do regimento comum e das duas casas legislativas, sendo a condução inicial do processo orçamentário levado a efeito por uma Comissão Mista de caráter permanente, a CMO, a qual na prática é a principal instância deliberativa e decisória acerca do conteúdo do orçamento público, uma vez ser incumbida de emitir parecer sobre projetos de leis orçamentárias, concentrar o processo de votação das emendas e acompanhar a execução orçamentária. Por fim, impende ao Plenário do Congresso Nacional votar a proposta de LOA e respectivo parecer emitido pela Comissão Mista, como etapa derradeira do processo legislativo. (SUPREMO TRIBUNAL FEDERAL, 2017, p. 66)

E o ministro Fachin ainda alerta: 
Na qualidade de lei ordinária, compete ao Chefe do Poder Executivo promulgála, após a sanção ou vetos cabíveis. A partir disso, instaura-se a fase de execução do ciclo orçamentário. Desse expediente argumentativo, conclui-se que o Poder Constituinte atribuiu ao Congresso Nacional a qualidade de locus político para a formação democrática de decisões acerca do orçamento público. (SUPREMO TRIBUNAL FEDERAL, 2017, p. 66)

Por conseguinte, a Constituição define que os limites da atuação do Poder Judiciário são estritos ao analisar decisões orçamentarias e o ministro reforça seu argumento citando inclusive Sunstein que afirma que "as decisões sobre quais direitos e de que forma cabem proteger e acerca de quanta riqueza social deve se investir deveriam estar sujeitas à crítica e ao debate público constantes em processos de deliberação democrática”. (SUNSTEIN, 1999, pp. 248, tradução nossa)

Desse modo, o ministro Fachin seguiu o caminho de verificar a legalidade estrita da proposta e decidiu pela improcedência da ação, pelo argumento principal de que não teria ocorrido vulneração da autonomia do Poder Judiciário, que elaborou sua proposta livremente.

Por seu turno, também decidindo pela improcedência da ação, o ministro Barroso argumentou que apesar de considerar que o pleito da ANAMATRA seria correto, não seria uma questão jurídica e se expressa afirmando que, "a queixa é legítima, mas acho que é uma queixa de natureza política e não uma queixa judicializável." (SUPREMO TRIBUNAL FEDERAL, 2017, p. 84), acreditando que não caberia ao Poder Judiciário pronunciar-se sobre o tema, porque não era uma situação grave nem excepcional que justificasse a intervenção em uma função que é precipuamente do Poder Legislativo.

O ministro Barroso decidiu por argumentar fundamentando-se, tal qual o ministro Fachin, somente em critérios jurídicos, analisando o caminho da proposta orçamentária, o cumprimento dos requisitos de validade exigidos pela Constituição, a ocorrência ou não de desvio de finalidade, julgando ao fim a ação improcedente.

Já o ministro Luiz Fux assume uma postura mais incisiva e chama atenção para a interdependência dos direitos com o contexto econômico:

Dito de outro modo, como regra geral, não há falar em direito adquirido a orçamento. Essa afirmação, embora pareça categórica, há de ser ainda mais enfatizada em matéria de rubricas orçamentárias destinadas à manutenção do aparato administrativo do Estado. Isso ocorre porque a própria estabilização de um orçamento fixo, além de estar "descolada" do cenário macroeconômico do país, acaba por incentivar um regime de menor produtividade (SUPREMO TRIBUNAL FEDERAL, 2017, p. 90)

O ministro Fux alerta para o cenário de crise, mostrando que escolhas ou trade offs estavam sendo feitos: "o Programa Nacional de Acesso ao Ensino Técnico e Emprego (PRONATEC) contou com redução de cerca de 60\% (de R \$ 4 bilhões, para R \$1,6 bilhão). (..) Programa Minha Casa Minha Vida (PMCMV), houve uma redução de quase 70\% (de R\$ 14bilhões para R \$ 4,3 
bilhões)". (SUPREMO TRIBUNAL FEDERAL, 2017, p. 24)

Outros ministros que assumem uma postura considerada mais clara sobre o contexto econômico são os ministros Lewandowski e Celso de Mello, mas indo para uma direção completamente distinta do ministro Fux. Veja-se que o ministro Ricardo Lewandowski em seu voto aduz que o corte realizado no orçamento da Justiça do Trabalho foi drástico:

É inegável que o corte drástico - diga-se «drástico» e absolutamente desproporcional em relação a outros ramos da judicatura - prejudica, sim, a prestação do serviço essencial à população que os magistrados do trabalho prestam exatamente à cidadania, que é a jurisdição. As instituições, como regra, o próprio Estado, são ficções jurídicas que integram. Essas instituições são pessoas, e essas pessoas se congregam, evidentemente, em associações que representam os seus interesses. Neste caso, os seus interesses estão claramente afetados (SUPREMO TRIBUNAL FEDERAL, 2017, p. 56)

E para o ministro Lewandowski, a crise econômica não seria um motivo para cortes no orçamento e sim para que se mantivesse a integridade da proposta enviada:

Portanto, neste momento de crise econômica, sobretudo em se ando de um incremento na taxa de desemprego que afeta os mais humildes, nós impormos um corte no orçamento da Justiça do Trabalho desta envergadura, sobretudo considerando os argumentos que foram veiculados pelo Relator do Orçamento, dirigidos, especialmente, esses argumentos, para a Justiça do Trabalho, parece que, em princípio, há algo que, não diria inconstitucional, mas, pelo menos, algo que não é salutar, considerado o quadro. (SUPREMO TRIBUNAL FEDERAL, 2017, p. 94)

Já para o ministro Celso de Mello, o Congresso Nacional havia incorrido em desvio de finalidade e postura abusiva que deveria ser corrigida. (SUPREMO TRIBUNAL FEDERAL, 2017, p. 111).

Essas observações deixam evidente algo importante, especialmente visando o combate de meios de interpretação dogmáticos: um único fato pode receber interpretações dissonantes. Não há encaixe, não há silogismo. A hermenêutica judicial é altamente complexa e intrincada.

No caso analisado, o argumento da crise econômica ora era usado para que a ação fosse julgada improcedente, pois justificaria os cortes feitos, ou ao contrário, era usado para amparar o julgamento de procedência da ação, por conta da possibilidade do corte orçamentário efetuado na Justiça do Trabalho ter o potencial de inviabilizar o funcionamento regular desse ramo do Poder Judiciário.

Em alguns votos vê-se um raciocínio em essência, juridico e minimalista. Em outros votos fica mais patente o uso de argumentos "extrajurídicos" ou de um tipo de racionalidade externa ao direito que tocam em ponto sensível. Esses argumentos estranhos ao campo juridico exercem uma incontestável força gravitacional e são no mais das vezes imbuídos de uma racionalidade externa aos paradigmas de racionalidade e especificação do direito e por isso entram na esfera jurídica 
através de interpretações que podem ser dissonantes.

Além dessas divergências interpretativas provarem a dificuldade em se achar as razões de decidir que possam ser atribuídas ao colegiado pela falta de debate entre os ministros, essa variabilidade na interpretação de um mesmo fato denota também esse obstáculo interno ao próprio direito.

O sistema juridico busca estabilidade e integridade, mas tem que lidar com o fenômeno de aplicação do direito a casos concretos, momento em que essa dificuldade fica evidente, ainda mais diante da complexidade social que arrisca submergir o sistema jurídico.

\section{CONCLUSÃO}

Se o direito positivo está sofrendo uma crise de legitimidade que passou a alimentar a concentração de poderes nas mãos dos intérpretes e aplicadores das decisões judiciais, caberá a estes destacar o papel do direito e saber as consequências de sua aplicação.

Cabe, sobretudo, o respeito à Constituição como lei fundamental. Mas o respeito à Constituição deve ocorrer através de uma visão não metafísica que observe direitos fundamentais e normas constitucionais como meios que permitem a mobilidade do intérprete entre racionalidades distintas e ao mesmo tempo, garantem a juridicidade da resposta, permitindo ao mesmo tempo, a atualização do sistema juridico que passa a compreender e ser sensível em relação as expectativas dos demais sistemas.

Nesse sentido, é preciso também considerar que a economia sempre está presente no processo de interpretação, seja explícita, seja implicitamente, pois a saída do paradigma metafísico pautado em dualismos como sujeito/objeto e a crença no ponto arquimediano possibilita a percepção de que o fenômeno de compreensão do mundo pelo intérprete é complexo e por isso caberá ao intérprete contemporizar os campos juridico e econômico e garantir a autonomia do direito.

Se há uma abertura demasiada para questões sociais prementes, o direito perde sua racionalidade própria e se transforma em sociologia. Se por outro lado foca no paradigma da escassez e desconsidera o aspecto juridico, o intérprete se pauta apenas pelo aspecto econômico, mas se a busca é apenas pela logicidade jurídica, sem ater-se aos demais aspectos, haverá alienação, através de uma espécie de fetichismo jurídico, tornando o direito somente retórica sem efetividade, palavras sem existência real porque até mesmo a liberdade não é nada se faltam os recursos para defendê-la. É então preciso a busca de um equilíbrio, não obstante a dificuldade dessa busca.

Considerar o processo de influências recíprocas entre sistemas implica em compreender que o direito não é estático, nem deve ser idealizado e substancializado em um processo hermenêutico que renegue qualquer circunstância exterior, sobremaneira o contexto econômico, relevante para que o direito encontre sua necessária efetividade.

Segue-se desse quadro que é preciso questionar e compreender como essa rede de influências é formada e como se mantém o padrão de racionalidade específico de cada área, de modo a impedir que o direito tome os procedimentos específicos do campo econômico e desse modo abandone a sua racionalidade particular. 
Enfim, a influência da economia no campo juridico é profunda em razão da própria importância do sistema econômico e o espraiamento de seus juízos de valor para toda a sociedade, mas é preciso analisar cuidadosamente essa influência recíproca e observar as formas de manutenção de equilíbrio e simbiose entre essas duas áreas distintas, com clareza e cautela.

Essa é uma questão complexa, mas é preciso começar a se perceber a economia não como inimiga do direito. É preciso começar a entender o raciocínio econômico de forma mais prática e simples, sem que toda interpretação judicial que considere aspectos econômicos sofra a pecha de utilitarista.

Enfim, é preciso sair do absolutismo e do essencialismo na questão da interpretação judicial e passar a considerar a efetividade e a interdependência de contextos, sob pena de excesso de legislação simbólica que acabe por trazer uma ficção constitucional tão profunda que traga consigo a descrença e o desvalor da Constituição.

Por conseguinte, hoje o que se enfrenta é muitas vezes um raciocínio de base metafísica e cunho essencialista para o direito, com grandes pensamentos sobre direitos fundamentais, proibição de retrocesso, dignidade da pessoa humana como valor imanente e por outro lado, há um pesado impacto do sistema econômico no sistema juridico com aumento da complexidade na interação entre ambos os sistemas, gerada dentre outros fatores, também pelas mudanças tecnológicas que questionam diuturnamente o modelo estatal de produção e domínio do direito, causando uma corrosão no papel do Estado e uma pluralidade de fontes e meios de intepretação. Com a crise do direito positivo, há cada vez mais predomínio do campo simbólico do direito, causando perda de efetividade e erosão constitucional.

Esse excesso de legislação simbólica pode levar à ideia de que seria preciso que o campo juridico se pautasse pelos ideais do campo econômico. Contudo, esse é apenas o modo mais açodado de lidar com a questão. Isso porque assumir a racionalidade econômica sem qualquer filtro no campo juridico seria uma postura que apenas causaria maior instabilidade.

E qual seria a solução? Um início seria realizar um processo de interpretação mais claro, com razões de decidir francamente expostas para permitir a compreensão do processo de raciocínio do julgador. Outro caminho seria tomar os direitos fundamentais como eclusas que permitem a interpretação do entorno do sistema jurídico e garantem que a resposta seja dada pelo direito.

Contudo, há que se percorrer um longo caminho até que essa visão seja alcançada e a análise do julgamento da ADIN 5468 debatendo suposto desvio de finalidade do Poder Legislativo deixou evidente a dificuldade, em uma questão de controvérsia extrema, dado o momento econômico e político do país que passa por uma crise econômica que foi ignorada tanto que as as alterações orçamentárias foram vistas sob o prisma de um viés ideológico contrário à Justiça do Trabalho e motivaram uma ação constitucional.

No julgamento foi possível perceber como os fatos econômicos são interpretados e considerados pelos ministros e ficou evidente a dificuldade em encontrar uma razão de decidir do colegiado. Além disso, muitos ministros adotaram uma espécie de substituição do raciocínio juridico pelo econômico e essa não é a solução. 
A solução passa por fortalecer a argumentação e os julgamentos através de processos claros, com a exposição de argumentos que busquem se manter nas margens da racionalidade jurídica. Não se pode tentar tomar a racionalidade econômica e centrar-se no paradigma de necessidades infinitas e recursos escassos. Cabe ao intérprete compreender e reinterpretar a seara econômica dentro do sistema juridico, da forma mais aberta e clara possível.

Mas por ignorar por tanto tempo o campo econômico, por conta da volatilidade permanente das instituições e das relações sociais, os intérpretes do direito por vezes não conseguem fazer essa reentrada dos fatos econômicos no sistema juridico de forma clara e acabam por abdicar da racionalidade própria do direito.

Não podendo mais ser desconsiderado o campo econômico, dado a gravidade da situação atual, em especial no Brasil, com diminuição debilitante da receita orçamentaria, esse passa a ser o grande desafio do intérprete face à situação atual: manter a racionalidade jurídica na aplicação do direito face a um mundo em constante transformação.

\section{REFERÊNCIAS}

ALEXY, R. (2011). Teoria da Argumentação. Rio de Janeiro: Forense.

ALEXY, R. (2011). Teoria dos Direitos Fundamentais. São Paulo: Malheiros.

ASSIER-ANDRIEU, L. (2000). O Direito nas sociedades humanas. São Paulo: Martins Fontes.

CÂMARA FEDERAL. (09 de fevereiro de 2016). PLOA. Brasília, DF, Brasil. Acesso em 07 de 09 de 2018, disponível em p://www.camara.gov.br/proposicoesWeb/prop_ mostrarintegra;jsessionid=6C2D4A80BB3E0C009644443F78BC7FE9. proposicoesWeb1?codteo $\mathrm{r}=1423589 \&$ filename $=$ Tramitacao-PLN $+7 / 2015+\mathrm{CN}$

CANOTILHO. (11 de 04 de 2015). A proibição de retrocesso . Acesso em 12 de 07 de 2018, disponível em https://www.conjur.com.br/2015-abr-11/observatorio-constitucional-proibicaoretrocesso-social-pauta-stf,

CARNEIRO, W. A. (2009). HERMENÊUTICA JURÍDICA HETERORREFLEXIVA. São Leopoldo: Unisinos.

CARNEIRO, W. D. (2018). Os direitos fundamentais da Constituição e os fundamentos da Constiuição de direitos: reformulações paradigmáticas na sociedade complexa e global. . Revista de direito Mackenzie, 130-165.

DWORKIN, R. (1999). O império do direito. São Paulo: Martins Fontes.

FARIA, J. E. (2010). Direito e conjuntura. Rio de Janeiro: Saraiva.

HEGEL, G. (2012). Fenomenologia do Espírito. São Paulo: Vozes.

HUME, D. (2001). Tratado da Natureza Humana. São Paulo: UNESP. 
HUNT, E. (2012). História do pensamento econômico. Rio de Janeiro: Elsevier.

KAUFMANN, R. O. (2010). Direitos humanos, direito constitucional neopragmatismo. BRASÍLIA: UNB.

LARENZ, K. (1991). Metodologia da ciência do direito. Lisboa: Fundação Calouste Gulbenkian.

MALINOWSKI, B. (1976). Argonautas do pacifico ocidental: Um relato do empreendimento e da aventura dos nativos nos arquipélagos da Nova Guiné melanesia. São Paulo: Abril Cultural.

MARCUSE, H. (2004). Razão e revolução: Hegel e o advento da teoria social. São Paulo: Paz e Terra S/A.

MASCAREÑO, A. (2011). The Ethics of the Financial Crisis En P. Kjaer, G. Teubner y A. Febrajjo (Eds.): Crisis in Constitutional Perspective: The Dark Side of Functional Differentiation. Oxford: Hart Publishing.

OITAVEN, D. (2016). A hermenêutica da esgrima e dos direitos humanos. Salvador: Jus podium.

PASSOS, J. C. (2013). Revisitando o direito, o poder, a justiça e o processo. Salvador: Jus Podium.

PORTELA, B. B. (25 de 10 de 2017). Previdência: Portugal criou jurisprudência de crise. São Paulo, SP, Brasil. Acesso em 07 de 12 de 2018, disponível em https://www.jota.info/ paywall?redirect_to=//www.jota.info/opiniao-e-analise/artigos/previdencia-portugal-crioujurisprudencia-de-crise-25102017

POSNER, R. (2007). Economic analysis of law. New York: Aspen Publishers.

POSNER, R. (2010). Direito, pragmatismo e democracia. Rio de Janeiro: Forense.

POSNER, R. (2010). How Judges Think. Cambridge, Massachusetts: HARVARD UNIVERSITY PRESS.

PRETZEL, G. K. (2014). PROCESSO DECISÓRIO NO SUPREMO TRIBUNAL

FEDERAL: APROFUNDANDO A METÁFORA DAS ONZE ILHAS. São Paulo: Revista de Estudos Empíricos em Direito.

RAWLS, J. (2010). Uma teoria da justiça. São Paulo: Martins Fontes.

SUNSTEIN, C. (1995). Incompletely Theorized Agreements. Harvard Law Review, Vol. 108, No. 7, 222-250.

SUNSTEIN, C. (1999). The Cost of Rigths. New York: WW Norron \& Company.

SUPREMO TRIBUNAL FEDERAL. (02 de agosto de 2017). AÇ $\tilde{A} O$ DIRETA DE

INCONSTITUCIONALIDADE $n^{\circ}$. 5468, REQUERENTE: ANAMATRA. RELATOR MINISTRO 
LUIZ FUX. Acesso em 02 de 10 de 2018, disponível em STF: http://portal.stf.jus.br/processos/ detalhe.asp?incidente $=4920998$

TEUBNER, G. (1989). O direito como sistema autopoiético. LISBOA: FUNDAÇÃO CALOUSTE LISBOA.

VELJANOVSKI, C. (1990). A economia do direito e da lei: uma introdução. Rio de Janeiro: Instituto Liberal.

VOLTARIRE. (1995). Cândido ou o otimismo. São Paulo: Nova Fronteira.

Como citar: SCHURIG, Alessandra Cavalcante Scherma. ROCHA, Júlio César de Sá. A influência do contexto econômico na interpretação judicial: na vida a gente pede o quanto quer e recebe o quanto pode. WTO-OSC/ds267 - Pland Cotton. Scientia Iuris, Londrina, v. 23, n. 2, p. 147-165, jul. 2019. DOI: 10.5433/2178-8189.2019v23n2p147. ISSN: 2178-8189.

Recebido em: 10/04/2019.

Aprovado em: 15/07/2019. 